\title{
Housing Mobility and Downsizing at Older Ages in Britain and the United States
}

\author{
James Banks ${ }^{\star}$, Richard Blundell ${ }^{*}$ Zoë Oldfield ${ }^{* *}$, and James P. Smith ${ }^{* *}$ \\ ${ }^{*}$ Institute for Fiscal Studies and University College, London \\ ${ }^{* * *}$ RAND \\ **Institute for Fiscal Studies
}

\section{Abstract}

This paper examines geographic mobility and housing downsizing at older ages in Britain and America. Americans downsize housing much more than the British largely because Americans are much more mobile. The principal reasons for greater mobility among older Americans are two fold: (1) greater spatial distribution of geographic distribution of amenities (such as warm weather) and housing costs and (2) greater institutional rigidities in subsidized British rental housing providing stronger incentives for British renters not to move. This relatively flat British housing consumption with age may have significant implications for the form and amount of consumption smoothing at older ages.

Population ageing has led to an increasing interest amongst both policy makers and academic researchers alike in the consumption and wealth trajectories of individuals and households at older ages. The broad issue is one of whether individuals are accumulating enough assets to fund longer retirements, but within that overarching issue are a number of other questions relating to the way in which resources are accumulated prior to retirement and the degree to which they are drawn upon after retirement. One such set of questions relate to housing wealth, the consumption of housing services, and the role that each plays in life-cycle accumulation and decumulation trajectories.

The empirical study of home-ownership trajectories at older ages has a long history, dating back to the first studies of 'downsizing' of housing in the US by Merrill (1984) and Venti and Wise $(1989,1990)$. Evidence from these and subsequent studies was somewhat mixed with regard to the extent to which individuals and households drew down their housing wealth when observed at older ages in the late 1980s and early 1990s.

In a recent cross-national comparative study, we examined downsizing in the US and Britain. We showed, using the same household data that will be used in this study, that housing downsizing was an important part of life for many older households in both countries over the period 1984-2006 (Banks et al. 2010). Figure 1, taken from that analysis, shows more specifically that amongst those who moved at middle and older ages there is, on average, a reduction in the number of rooms in household residences as age increases. This reduction is somewhat larger in the United States than in Britain but is apparent in both countries, regardless of whether one looks at the raw data or controls for other marital status, family size, or employment transitions that occur with age. Other measures of downsizing, such as the change in gross house value for movers, demonstrated the same patterns. 
When one looks at the population level rather than only movers, however, the evidence points to much less downsizing in Britain than in the US. Figure 2, taken from the same study, shows that across all families aged 50 or more downsizing was much less common in Britain compared to the US. The two figures together suggest that the main factor underlying lower rates of downsizing in Britain is a much smaller frequency of moving amongst older households in Britain compared to America. This paper aims to investigate the reasons for this quite different pattern of residential mobility at older ages in the two countries.

In this paper we document and model housing mobility choices of the middle-aged and elderly in Great Britain and the United States. We show that the differential in mobility rates is particularly high among renters, indicating that a simple explanation of higher transactions costs for owner-occupier movers is unlikely to be the full explanation. Hence, we will examine a number of other potential factors. There are several reasons for housing mobility at older ages, including demographic transitions, particularly those associated with marital transitions and/or children leaving home, and labor force transitions primarily at these ages into retirement. But individuals may also move at older ages to consume higher levels of amenities such as a warmer winter climate, or to reduce the cost-of-living. Cost-of-living factors may include lower housing costs for either renters or owners or lower income taxes.

For many factors thought to induce greater mobility at older ages, there may be simply less opportunity in Britain to achieve these goals given the much smaller geographical size. Temperature and sunshine may exhibit less within-country variation, taxes and other location specific costs may be less spatially variable, and the structure of local tax rates may be more uniform in Britain compared to the United States. Hence we will document the extent of within-country variation in factors that are believed to encourage migration among older people and the degree to which actual moves that are made among older people appear to buy better amenities and lower taxes.

Higher mobility frictions may also differentiate the two countries. Many British renters have lived in council houses for long periods of time at subsidized rents with long waiting lists for new admissions. The incentives to remain in place for these people may be quite high. Higher transactions costs may also be associated with home ownership in Britain due to stamp taxes on sales of home. Taking into account all the factors mentioned in the last few paragraphs, these mobility decisions for renters and owners in both countries will be modeled separately in this paper. We will also separately model moves that take place within a British region or US State and those that cross between them, in order to separate out local amenity effects from those of national institutional differences.

This paper is divided into five sections. Section I describes the data sources used in both Britain and the US. Section II documents the principal facts about differential mobility of older households in Britain and the United States and describes their implications for housing consumption at older ages. In Section III we summarize the major factors that may produce differential mobility between these two countries. Section IV presents the results of models predicting mobility in the two countries for both renters and owners. In the final section, our principal conclusions are highlighted.

\section{DATA}

This research will rely on micro-data from the US (the Panel Survey of Income Dynamics (PSID)) and Britain (the British Household Panel Survey (BHPS)). Besides the standard set of demographics on age, schooling, family income, marriage and other aspects of family building, information available in all these surveys include several aspects of housing choice -ownership, size of house, and value of house. 


\section{The Panel Study of Income Dynamics}

The PSID has gathered 40 years of extensive economic and demographic data on a nationally representative sample of approximately 5,000 (original) families and 35,000 individuals who live in those families. Details on family income and its components have been gathered in each wave since the inception of PSID in 1969. Starting in 1984 and in five-year intervals until 1999, PSID asked questions to measure household wealth. Starting in 1997, the PSID switched to a two-year periodicity, and wealth modules are now part of the core interview. Our analysis uses PSID data from the years 1969 to 2005. Attrition in the PSID is very low, averaging a few percentage points each wave (Becketti et al., 1988; Fitzgerald et al., 1998).

In each wave, the PSID asks detailed questions on family size and composition, schooling, education, age, and marital status. State of residence is available in every year and individuals are followed to new locations if they move. Unlike other American wealth surveys, PSID is representative of the complete age distribution. Yearly housing tenure questions determine whether individuals own, rent, or live with others. Questions on value and mortgage were asked in each wave of the PSID. Renters are asked the rent they pay, and both owners and renters are asked the number of rooms in the residence. In this paper, we use PSID data for the years 1969 through 2005.

\section{British Household Panel Survey-BHPS}

The BHPS has been running annually since 1991 and, like the PSID, is also representative of the complete age distribution. The wave 1 sample consisted of some 5,500 households and 10,300 individuals. The BHPS contains annual information on individual and household income and employment as well as a complete set of demographic variables and has several other features to recommend it. There is an extensive amount of information on mortgages and housing (including number of rooms) that enables us to measure housing wealth in each wave of the data. ${ }^{1}$ Regional variation in ownership and housing wealth accumulation will be essential in our tests and the data will provide us with sufficient observations per year in each region to carry out our tests. We use BHPS data for the years 1991-2007.

Throughout the paper, the unit of analysis is the individual. A family is defined as a single person or a couple (and any dependent children they may have). Any demographic information included in the analysis such as age or education relates to the individual. Financial information (income and wealth) is defined at the "family unit" level. This means that each individual is assigned the sum of income and wealth that they and their spouse have. We take care to define tenure in terms of the family unit rather than the household. In both countries, an individual is defined as an owner or a renter only if they are the individual (or the spouse of the individual) responsible for the property. This is to ensure that adults living in accommodation with other family members are not lost from the analysis as subsidiary adults in households headed by other individuals. Hence an 80 -year-old living rent-free with their adult children in an owned property is not defined as an owner (unless they own the property jointly) — they would be captured in our "other tenure" group.

\section{TENURE STATUS AND TENURE TRANSITIONS}

\section{Homeownership rates and tenure transitions at older ages}

Especially at older ages most Americans are homeowners. Based on multiple waves of the PSID and BHPS, Table 1 presents tenure status for individuals by age for ten-year age groups starting at age 50 , concluding with a residual category of those 80 plus years old. To

\footnotetext{
${ }^{1}$ With the exception of 1992 when house value was only collected for those living at new addresses.
} 
eliminate any differences due to a secular trend toward increased home ownership at older ages which exists in both countries, tenure status is defined over the same post-1990 time period in both countries. Table 1 shows that more than four in five of all Americans over age 50 are homeowners. Fifteen percent of Americans in this age group are renters, while a relatively small fraction are in the catch all 'other categories' that largely consist of those living with relatives or in a nursing home. ${ }^{2}$ Among older Americans, there is a decline in the fraction who are home owners across age groups after age 70, especially for those above age 80 where the home owner rate is only $63 \%$. Most of the decline in the probability of owning a home appears as an increase in renting but some of it, particularly among those over age 70 , reflects an increase in the likelihood of living with others or in a nursing home.

For British individuals over age 50, the probability of being a homeowner is about twelve percentage points lower than that of Americans, a deficit mostly offset by a higher probability of renting. There exists a much sharper negative homeownership age pattern in Britain compared to the US in Table 1. Among those in their fifties for example, there is about a four percentage point difference in home ownership rates between the two countries -by ages $80+$ the likelihood of owning a home is 15 percentage points lower in Britain compared to the US. As documented in Banks et al. (2003), this sharp negative age gradient in home owning rates in Britain largely reflects cohort effects associated with the sale at subsidized rates of government owned council housing that made the previous renters now owners.

\section{Changes in housing tenure with age}

The very pronounced cohort effects in housing status in Britain mentioned in the previous section indicate that it would be perilous to attempt to read housing transitions from crosssectional age housing tenure patterns, especially in Britain. Instead, in this section the most salient transitions are highlighted using the panel nature of the data in the US and Britain.

Since much of the existing research on downsizing at older ages focuses on the decision to sell one's original home and become a renter (Venti and Wise 2001; Sheiner and Weil 1992), we begin with transitions conditional on originally being a homeowner. Table 2 examines these post 1991 tenure transitions in the United States (using the PSID) and Britain (using the BHPS) for a sub population who are at least 50 years old and who were originally home owners in the initial period. ${ }^{3}$ Because the extent of any transitions that take place will depend on the length of the window during which households are allowed to adjust their status, the data are presented for five year durations between waves of the panel. Table 3 organizes the data in precisely the same way for those who were initially renters. We separate transitions in this data by the nature of the tenure transition-i.e., whether to owner or renter in the new home, and within these categories by whether the move went across a state line in the United States or across one of nine regions in Britain.

Over a five year period, more than one in every five American home owners who were at least 50 years old moved out of an originally owned home. Among Americans who did move, however, three-quarters remained homeowners by purchasing another home. Another

\footnotetext{
${ }^{2}$ Both PSID and BHPS understate tenure status of 'other' especially those listed in 'assisted living' places. When they started, both surveys were samples of the non-institutionalized populations, although those who subsequently move into nursing homes and other forms of assisted living remain in the survey. The implications of this baseline year sampling are obviously greater in the BHPS than in the PSID since 1991 is the baseline year of BHPS. But even PSID under-represents the institutionalized population since when given a choice between spouses with one of them in a nursing home and the other in a community dwelling the PSID always chooses the later.

${ }^{3}$ To the extent that owner occupiers' retirement-related mobility yields movements outside Britain—to Spain and France, as opposed to Florida and Arizona, for example — such transitions are of course not captured in our BHPS data although the empirical importance of such transitions in Britain is limited as we discuss briefly below.
} 
$20 \%$ of them became renters while the rest do a combination of things, including moving in with family members or into group dwellings. Mobility among homeowners is clearly less in Britain for older households. Across the same five year span, about one in every eight British homeowners relocated compared to about one in five American households. If we extend the horizon over which we examine mobility to ten years instead of five, one in every three American home owners would move compared to one in every four British homeowners.

Table 2 also shows that the majority of moves of home owners take place within the same region or state of their original home. In both Britain and the United States, $80 \%$ of the moves that homeowners did make left them residing in the same region or state of their original residence.

We turn next to the age pattern of mobility among homeowners. In the United States, amongst those who do move, the fraction that do not purchase another home increases with age-at older ages American owner occupiers increasingly move into rental properties and to a lesser extent into either assisted living or to stay with family members. The probability of a homeowner moving into a rental property is far less in Britain than in the US and it is a good deal less likely at older ages for an home owner in Britain to subsequently become a renter.

Table 3 demonstrates—not surprisingly— that renters in both countries are far more mobile than owners. Across the five year survey interval, almost two-thirds of American renters moved at least once compared to only one-in-five British renters. Once again, the majority of moves amongst American renters are within-state residential moves, but this is especially the case when the move is from one rental property to another. One in five American moves from rental to owner tenure status is across state lines.

British renters are far less mobile than their American renter counterparts, a much larger between country mobility differential than that which existed among home-owners. In the US, about half of originally renting households remained so and simply settle into another rented apartment or flat. But around $40 \%$ of American renters who do relocate over age 50 subsequently become homeowners. The comparable British number is less than half that eighteen percent. In the US and in Britain, renters become increasingly less mobile with age. Forty-four percent of American renters in their seventies stay in the same place over a ten year horizon compared to $33 \%$ of American renters in their fifties. Eighty-nine percent of British renters over age 80 stay in the same place.

\section{FACTORS RELATED TO GEOGRAPHIC MOBILITY}

Why is there so much less mobility at older ages in Britain compared to the United States? To attempt to address that question, Table 4.a lists summary statistics about the distribution of state level attributes that are potentially related to migration across states in the United States while Table 4.b displays a similar but not identical array of attributes for regions in Britain. These attributes include measures of spatially specific amenities that make a location an attractive place to live or not and the economic costs associated with living in one place rather than another. In addition to the mean, our summary stats on spatial distributions include minimum and maximum values, and the $90^{\text {th }}$ minus $10^{\text {th }}$ percentiles and $75^{\text {th }}$ minus $25^{\text {th }}$ percentile, both expressed relative to the median value.

There is considerable variation amongst American states in spatial amenities compared to those in Britain - in particular mean winter temperature, hours of sunshine in January, and yearly rainfall. For example, the January spread between the $90^{\text {th }}$ and $10^{\text {th }}$ percentile state is equal to the median temperature State- thirty one degrees Fahrenheit. In contrast, in Britain 
the spread between the coldest and warmest region in January is only three degrees Fahrenheit. While the contrast between the two countries in the other spatial amenities is not as extreme, in all cases there exists far more diversity in the US compared to Britain. In general, and largely due to the much smaller size of the country, these types of spatially specific amenities are unlikely to generate much within country migration in Britain as there simply exists so little geographic variation that the opportunities to improve your lot through migration are quite small. This is clearly not the case in the United States. ${ }^{4}$

Turning to economic variables that might be related to migration, we focus on the following dimensions in the US - income taxes and rental and owning price of housing. Once again, there exists considerable variability across American States especially compared to limited regional variation in Britain. Some of this is inherent in governance difference between the two countries in the fiscal role assigned to local government units compared to the central government. In the US, income taxes are set at both the individual state level and a common federal level and states and local communities can also access property, sales, and occasionally income taxes. In Britain, the only major tax set at the local level is the council tax. This tax was introduced in 1993 (its predecessor was the community charge or poll tax). It is paid by both renters and owners and the level is roughly related to the value of your home.

Since tax rates vary by income in the United States, we characterize the geographical distribution of taxes by a small set of average tax rates per state. These tax rates are computed at four real income levels in each year $(\$ 20,000 ; \$ 40,000 ; \$ 60,000$ and $\$ 80,000$ ) for each state using the NBER Taxsim program. A family is assigned the tax rate closest to their family income. Average tax rates are a more appropriate indicator of tax incentives than marginal tax rates in this case since location choices are discrete (see Diamond (1980) or Griffith and Devereux (1998)). Not surprisingly, average tax rates by state increase significantly with income. Evaluated at the mean, average tax rate at the highest income is $20 \%$, four times that at the lowest income group-5\% at the lowest income level. For mobility decisions, it is variation in average tax rates among states at a given income level that is relevant. For those with low incomes, variation in average tax rates across states is relatively small and thus provides little incentive for mobility. For example, the difference in average tax rate at the $90^{\text {th }}$ and $10^{\text {th }}$ percentile is only $2.5 \%$ in the lowest income group. Variation in average taxes does increase as income rises. Comparing the $90^{\text {th }}$ to $10^{\text {th }}$ percentile, the difference in average taxes is 6 percentage points in the highest income group compared to 2.5 percentage points in the lowest income group.

Similarly, the average price per room whether computed as house price per room for owners or rental price per room for renters varies much more across American states than across British regions. Relative to the median, the spread between the $90^{\text {th }}$ and $10^{\text {th }}$ percentile in house price per room is 1.4 in the United States compared to 0.5 in Britain. Variation in rental prices shows a similar contrast between the countries. Using the same metric, relative to the median, the spread between the $90^{\text {th }}$ and $10^{\text {th }}$ percentile in rental price per room is 1.6 in the United States compared to 0.50 in Britain. These relative housing cost variations are a combination of the composition and quality of dwelling types and the cost of the area across the 50 US states or the 12 British regions.

\footnotetext{
${ }^{4}$ One possibility is that migration to Spain or other warmer parts of Europe leads to attrition from the BHPS data whereas equivalent migrations take place internally in the US and hence respondents remain in the PSID sample. Official statistics on migration show that the total numbers of out migrants age 45 or over was 33,000 in 1991 and 68,000 in 2006. Given population totals for those aged 45 and over in the same years these equate to outmigration rates of $0.015 \%$ and $0.028 \%$ respectively. Whilst this represents a large increase proportionately over the period of our sample, the numbers are far too low to be driving differences observed between mobility rates in the PSID and BHPS data. Hence we ignore international mobility for the rest of our analysis.
} 
The final row in Tables 4.a and 4.b captures a different aspect of geographic mobility by showing the fraction of rental homes that are subsidized in some way by government. There are two dimensions of subsidies that are recorded in the PSID-whether you live in a public housing project and whether a government subsidies part of the rent. ${ }^{5}$ Families in subsidized housing may be more reluctant to move or less able to move whilst retaining their subsidy. In the United States in 1995, about one in four renters aged over 50 live in some form of public or subsidized housing but once again there is a great deal of variation across states in this proportion.

In Great Britain, subsidized and public rental accommodation makes up a much larger proportion of the rental market particularly for the over fifties. There are two main programs providing financial support for housing. Both are aimed exclusively at renters and are means tested. The first is a system of subsidized housing, often referred to as local authority, social or council housing. ${ }^{6}$ Those who are allocated a property will pay a below-market rent and the landlord will be either the local authority or a housing association. Individuals who are entitled to such a property are placed on a waiting list until suitable accommodation becomes available. ${ }^{7}$ Whilst entitlement to live in social housing is subject to a strict means test, once allocated a property, tenants can usually stay for life irrespective of any changes in circumstance. $^{8}$

The second program of financial assistance for British renters is the housing benefit system which was introduced in the late 1980s. This is a substantial component of the British welfare system and is simply a cash transfer from the government to the renter. It is not tied to a particular property but it is subject to a strict means test. The amount of benefit received is determined by personal circumstances and also the characteristics of the property (for example, whether the house is a reasonable size for the family). Housing benefit payments may fully cover the total amount of rent or may only partially do so. Social renters are also entitled to receive housing benefit if they pass the means test.

Table 4.b, which shows proportions of renters living in social housing, reveals that $81 \%$ of renters aged over fifty in Great Britain live in public rental accommodation (either local authority housing or housing association housing). The comparable fraction in the United States is only $27 \%$. In Britain, there is little escape from the large role played by the public sector in the rental marker as this proportion varies from $60 \%$ to $90 \%$ across the regions. Of those living in social housing, around 50\% also receive housing benefit (not shown in table).

Social renters have a severely reduced incentive and ability to move or to downsize their property for several reasons. Even if a tenant's current circumstances means that they are still entitled to social housing, moving can be very difficult because of the shortage of social housing: existing tenants are treated in the same way as new applicants, so if they are not in a priority group they may not be allocated a different property. For those whose circumstances have changed in such a way that they would no longer be entitled to social housing if they were to reapply, there is a large incentive not to move as they may not be allocated a different property at all and may have to move into the private sector and pay full market rent.

\footnotetext{
${ }^{5}$ Section 8 Rental Voucher Program increases affordable housing choices for very low-income households by allowing families to choose privately owned rental housing. The public housing authority (PHA) generally pays the landlord the difference between 30 percent of household income and the PHA-determined payment standard about 80 to 100 percent of the fair market rent (FMR). The rent must be reasonable. The household may choose a unit with a higher rent than the FMR and pay the landlord the difference or choose a lower cost unit and keep the difference.

${ }^{6}$ For more detail of the system of social housing see http://sticerd.1se.ac.uk/dps/case/cr/CASEreport34.pdf.

${ }^{7}$ Typically waiting lists are long. Priority is given to groups who are deemed most in need, including households which include dependent children, pregnant women, and the mentally ill.

${ }^{8}$ This system is currently under review.
} 
Receiving housing benefit may also reduce the incentive to downsize. For tenants who receive housing benefit that fully meets the cost of the rent, moving into smaller or cheaper accommodation would reduce their housing consumption and would have no offsetting reduction in cost. The disincentive to move is somewhat reduced for renters who receive housing benefit that only partially covers the rent, although it is still present. Whilst a reduction in housing consumption would lead to a reduction in housing costs, this might not be a one-for-one reduction due to the partial subsidy.

Our multivariate analysis will control for both social renting and receipt of full or partial housing benefit subsidies. Table 5 highlights large mobility differences among British renters depending on whether they are a social or private renter and within these categories depending on the extent of the benefit subsidy. Social housing is highly correlated with mobility rates- $37 \%$ of private renters move over a five-year period compared to only $16 \%$ of social renters. Among social renters, they least mobile are those who are receiving no social benefit and who presumably may have difficultly qualifying for a social flat if they moved. Care needs to be taken because there are many other differences across the various groups, not least in their average incomes. Hence further discussion will be left to the multivariate models of section four.

\section{Geographical mobility and the changes in amenities for movers}

Even when older householders remain home owners and stay in a home of about the same size, they can purchase improved spatial amenities and lower their costs of living by moving to places where amenities are better and/or costs are lower. Once one moves to a new place and leaves the old, one buys the entire package of amenities and economic costs and benefits of the new location compared to the old. It is possible that one may gain in one dimension (a more pleasant climate) at the expense of another (a more affordable place to live).

In this section, we summarize results obtained from our analysis of the change in spatial amenities and economic costs associated with mobility among HRS and BHPS respondents who are at least 50 years old. Due to data limitations, these amenities can only be measured at the region (in Britain) or state (in the United States) level even though there are differences in amenities and economic costs associated with within-region and within-state moves, especially in the United States. Since the desire for better amenities and lower costs may be age dependent, we include in all models a set of age dummies for the age intervals $50-59,60-69,70-79$, and 80 plus. In these models the constant term is suppressed. The British data spans years 1991-2007 while the American data spans years 1969-2005.

In this analysis, our aim is simply to describe the nature of changes observed in the two datasets. However, due to the small number of moves observed, particularly across regions, in some country-age cells we want to be sure that any differences are statistically significant. Hence we estimated models with a discrete outcome-being either the change in amenity or economic cost associated with a move — and a set of categorical age dummies as explanatory variables. In addition, this allows us to make certain that our comparative results are not affected by secular trends given that the data in the two countries covers a different time period. We therefore include a dummy variable in the American models for the years 19912005 , which are the years where BHPS data are available. That dummy variable is never statistically significant.

Table 6 summarizes our results for spatial amenities. We will illustrate our format with mean January temperature. A positive number in this table indicates that the area that a person left was colder than the area to which they moved - that is, a household was purchasing some additional warmth in the winter. Most of the American numbers in Table 6 are positive, indicating that on average American movers are going to warmer winter 
climates. Buying additional warmth during winter months is more common among those under 70 years old and is particularly large among those who move during the retirement years. Among those 60 to 70 years old, when most retirement-related moves take place in the United States, American across state movers 'purchase' six and half degrees Fahrenheit warmer winter climates. This may well be an understatement given the absence of data within states on amenities. Especially around the retirement age span and given the size of some American states, movers may well be heading for the warmer, more pleasant areas of the State which often are in the southern most parts. Not only is the new location more pleasant, winter heating costs are presumably lower in the new locale.

For those above age 70 , and particularly over age 80 , Americans actually move to slightly colder winter climates indicating that moves at very old age may reflect quite different motives, such as being closer to relatives (moving back to where relatives live) when elderly parents become increasingly frail and dependent. Sample sizes are also much lower at these older ages, making the patterns more erratic.

Not surprisingly in light of the data presented above in Table 4.b about the lack of variability in spatial amenities, our estimated models for Britain show virtually no relation between a region's winter climate and the direction of a move. The estimated coefficients are never statistically significant and are as often negative as positive.

Rainfall does not appear to be an important amenity inducing across region or state migration. Annual rainfall generally tends not to be statistically significant. In the three cases where we do find an effect, those aged 60-69 in the US and 50-59 in Britain move towards slightly wetter climates, while those aged $80+$ in Britain move away from such areas. Rainfall is a complicated amenity - while constant rain is not a desirable trait, hot dry summers (particularly in the US) are also associated with lower rainfall.

The other amenity that does appears to matter was hours of January sunshine. ${ }^{9}$ American movers across states apparently not only desire warmth but also sunlight. For people who move across state, January sunlight hours increase by almost seventeen hours in the retirement age span and about nine hours for movers in their fifties or seventies. Once again, this pattern disappears among the elderly where there is no improved sunshine for those over 80. In Britain, our model shows that once again there is little opportunity for gain for the British in terms of sunshine achieved through migration. In fact, among those in their fifties the days become a bit darker when people in Britain moved across regions.

We next consider in Table 7 changes in costs associated with the move by comparing average state housing and rental prices per room of the new location compared to the previous one. To avoid confusion in the units associated with switching between owner and rental prices when the move involves a change in tenure, prices in the destination location reflect the same type of tenure of the location of origin. To illustrate, if the move was from owner to renter, we compare mean state housing (as opposed to rental) prices in the two locations. To eliminate the confounding effect of housing price inflation, we compare origin and destination housing prices in the wave prior to the actual move. In addition to modeling these changes in cost per room by tenure status at location or origin, we also estimate models separately by whether the transition was to an owner or rental status.

In the US, homeowners in the retirement age span apparently move to less expensive places per room than those that they left, particularly when they remain owners. Owners who remain owners and who are moving across state boundaries are associated with average state

\footnotetext{
${ }^{9}$ We examined two other amenities-June relative humidity and July temperature- but did not find an association with mobility.
} 
costs about one thousand nine hundred dollars less per room. In contrast, there appears to be no real association with area specific costs per room among renters. Thus, holding the number of rooms constant, owners (but not renters) who migrate across state lines do appear to be moving to less expensive states.

Similar to the US, it appears that when British owners move when they are less than 70 years old, they also on average move to a less expensive region. Essentially at these ages, people are moving from the city (expensive) to the country (cheaper). Almost all of this effect is associated with moves where the person remained a home owner. In contrast, British renters who move experience no statistically significant cost change per room.

Especially in the United States, these location specific costs might include income or property tax changes which can vary considerably across states and localities. Property taxes are set at the local level in the United States so that they are outside the scope of our analysis. As described above, we computed average tax rates (combined federal and state) associated with a state for four different income levels with people assigned the income bracket closest to their actual income. Since taxes can change both due to a change in average income tax rates between the two locations or a change in income of the household, we evaluate the impact of changing taxes by holding income constant at the time of the move. By doing so, the pure impact of income tax rates can be isolated.

Table 8 lists changes in income tax rates associated with a move. For Americans over age 50 but under age 70, average state and federal taxes are lower after the move. The changes are relatively small-a little less than two percentage points. To some extent, the impact of income tax variation is undoubtedly understated in these computations due to the use of the only four income brackets to assign tax rates, it does not appear at present that this may not turn out to be a primary motive for migration in the pre-and post-retirement years. Once again reflecting a pattern seen before, this pattern reverses after age 70 when economic factors apparently play less of a role in the migration decision.

In sum then, how would we characterize mobility in terms of the overall cost implications for housing consumption? We know from Figures 1 and 2 that that Americans, and to a much less extent the British, tend to downsize during these ages so that when they move they select smaller homes which by itself would make them cheaper. This is true for both owners and renters. This downsizing alone would imply that less housing is being consumed and less is being spent on housing. For Americans and British homeowners, especially if they remain owners as most do and are less than 70 years old, the price per room is also lower in the new location compared to the old augmenting the lower expenditures on housing for across region and state moves.

\section{MODELING MOBILITY AT OLDER AGES}

In this section, we present our full empirical models of mobility at older ages in the US and Britain. Reflecting our discussions above, several factors hypothesized to be related to mobility at older ages are included in our analysis. These are conceptually organized into four groups-economic, family, location specific amenities, and institutional constraintseach of which potentially vary across our spatial units which will be States in the US and regions in Britain. Inter-state (or inter-region) migration is modeled separately from all moves.

Individual economic indicators in both countries include the ln of real annual family income and education. In the United States education is separated into three groups-13-16 years of schooling, 16 or more years of schooling with 12 or fewer years the reference group. In Britain, broadly comparable groups are constructed based on educational qualifications- the 
lowest education (reference) group are those with compulsory schooling only, the middle group has some post-compulsory schooling or vocational qualifications but less than a college degree, and the final group has college degrees or higher. The models also contain measures of individual values of baseline house value, the amount of home equity (for home owners only), and the average amount of inflation adjusted financial assets in the family. ${ }^{10}$

In addition to economic indicators measured at the individual level, our mobility models include measures of area specific housing costs—either mean rents per room (for renter models) or mean housing price per room (for the owner model). In the United States, we include a measure of the average income tax rates. As described above, these tax rates were computed based on year, state, and income of respondents.

The probability of moving may be related to work transitions especially those induced by retirement that take place at these ages. Therefore, a set of work transitions are entered into the models (work-no work, no work-work, no work-no work with work-work as the omitted category). All work variables are defined at the individual level but if the family unit is a couple, we include these work transitions for both partners.

Family related forces include whether there were any demographic transitions in the household in terms of marital status, whether any children are at home, and the number of people in the household. More specifically, all models have the following sets of demographic variables - a quadratic in age, the change in the number of people living in the house, three marital status transitions (married-single, single-married, single-single with married-married as the omitted group), and children living at home transitions (kids-no kids, no kids-kids, no kids-no kids with kids-kids as the omitted group ${ }^{11}$ ). The marital and child transition indicators tell us, conditional on changes in number of residents, whether changes in the type of resident living in the home matters.

While neither PSID nor BHPS have extensive measures of health, they do measure health status along the standard five point scale—excellent, very good, good, fair, and poor. ${ }^{12}$ Using this information, we construct two variables about health change between the waves of the panel-whether your general health status improved and whether your general health status got worse. The reference group is that your health status remained the same.

Based on our results above, our amenity measure is mean temperature in January. Institutional factors are meant to capture institutional arrangements in the two countries that may promote or inhibit mobility at older ages particularly among renters-whether one lives in public or subsidized housing (in the US) or in council housing in Britain. All area specific variables are interacted with age being at least 70 to gauge whether the influence of such factors vary with age.

Data used for estimation are based on a sample of individuals ages 50 and more using the PSID for the US (years 1968-2005) and the BHPS for Britain (years 1991-2007.) ${ }^{13}$ Separate models were estimated for owners and renters and all models include a linear time trend. Tables 9 and 11 (for owners) and Tables 10 and 12 (for renters) list estimated

\footnotetext{
${ }^{10}$ In the PSID and BHPS, information on assets is collected every five years so financial assets cannot be a time varying variable. We average financial assets (inflation adjusted) over the panel waves of the data and use that as our index of the financial liquidity of the family. For the BHPS, changes to question wording between 1995 and 2000 led to issues of comparability across waves. For this reason, we average financial assets across the two waves of data for which we have a strictly comparable measure (2000 and 2005). We include a dummy variable which controls for observations with missing wealth (the coefficient is not reported in Tables 9-12).

${ }_{11}$ For Britain, due to lack of observations in "no kids - kids" group, it is combined with "no kids-no kids" group.

12 The BHPS question asks about health status relative to others of your own age.

13 Although BHPS sample began in 1991, data on house value was only collected for those who were interviewed at a new address in 1992. Since our models are based on differences, we effectively have data starting in 1993.
} 
coefficients and associated $\mathrm{z}$ statistics obtained from OLS models of three types of migration decisions in the US and Britain - the probability of changing residence (regardless of destination), the probability of moving across a state or region boundary, and the conditional probability of moving across a state or region boundary given that you relocate. All decisions are modeled over a one year time frame.

If we examine first the set of transition variables included in the model for the US (marriage, kids, and work), the stable no transition reference group (married-married, kids-kids, and work-work) is generally the one least associated with mobility for both owners and renters alike. The transition into marriage generates the highest probability of a move, both within and across state moves. For Britain, a very similar pattern is found in that the most stable reference group is generally least likely to move, but the impacts of the marital transitions on mobility are typically quite smaller.

All 'kids' transitions motivate additional mobility both within and across states for renters and owners alike in the US. Especially for owners, the transition from no kids to kids in the home is associated with a move across states and for higher induced mobility (compared to the other types of kids transitions) for renters. This is most likely due to parents moving to their child's home and place of residence as they get older. The effect of these children transitions is once again similar in Britain but not as pronounced.

Work transitions also generate mobility both within and across states for both renters and owners in the US and in Britain. This is the case for one's own work transition and those of one's spouse or partner. The transition from work to non-work by either partner, which in this age group is most likely associated with retirement, induces households to move across state and region boundaries, presumably as the link between place of work and place of residence is broken. We find little systematic association of changes in health with mobility in either country although it is important to remember that the measurement of health is not a strength of either the PSID or BHPS.

We next describe estimated impacts of economic variables. Several dimensions of economic resources are measured, including household income, education, house value and home equity among home owners, and average financial wealth holdings. In the United States, statistically significant positive effects on the probability of moving are estimated for education and income, and higher incomes and more schooling are also more likely to generate inter-states moves in the US. Given the phase of the life-cycle we are examining, income is mostly not a proxy for job market opportunities in alternative labor markets. Instead these income effects are more likely to capture the ability to finance moves or to purchase amenities associated with localities that are no longer tied to jobs.

While average financial assets among American home-owners do not appear to be related to within State moves, more financial assets discourage across state moves. One interpretation may be that home-owners with little financial liquidity (controlling for net equity in their home), relocate in order to achieve greater financial liquidity. We find the same effect for across region moves of home owners in Britain and in both countries this effect is mitigated among older people. Greater financial assets encourage renter mobility in the United States but have no association with mobility in Britain.

In Britain, economic status variables — schooling and income - are far less important for mobility outcomes than in the US. We find a significant positive effect of education on the probability of moving but only for renters. There is no income effect on the probability of moving, either unconditionally or conditionally, for owners or renters alike. 
Conditional on being a homeowner, mobility rises with the value of the house but declines with home equity when both variables are in the model both in the US and Britain. One interpretation of the home value effect (in addition to a normal income effect) is that as the value of home goes up people are consuming a lot of housing relative to their income, inducing them to want to downsize their house. Conditional of the value of house, an increase in home equity is equivalent to a reduction in the stock and flow of mortgage payments, which makes it less likely that people move to reduce those payments. In both countries, these house value variables do not affect whether or not the move is inter or intrastate (with the exception of a possible positive effect of ln house value on probability of moving regions in Britain).

There are several indicators of the economic costs associated with living in one's current location-average income tax rate (US only), council tax rate, ${ }^{14}$ cost of housing per room (house price per room for owners and rental price per room for renters), and the fraction of rental residents of that state who live in public or subsidized housing. Based on transitions tables discussed above, all variables are interacted with whether the respondent was 70 years old or older.

Among owners, higher state or region wide cost per room encourages additional mobility and makes it more likely that the move is across states in the United States or regions in Britain. These effects become smaller in Britain and for those over 70 years old. Among renters in both countries these effects are weaker with the only statistically significant effect being that high rental costs per room encourage mobility across regions among British renters.

Conditional on moving, a high income tax in the origin state encourages additional across state mobility among owners. Renters in high tax states are discouraged from moving, although once again if they do move it will be across state.

Finally, a larger fraction of state rental units in public or subsidized housing discourages mobility in the US, although this effect is quite small. In Britain, for owners, the fraction living in public housing (local authority housing) in a region has a negative effect on the probability of moving. For renters, the proportion living in public housing in the region also discourages mobility, but it has a positive effect on the probability of moving region both unconditionally and conditionally. When an area is dominated by public housing which is often characterized by long queues, it may be very difficult to find alternative rental properties unless one is willing to move from the region.

Given our previous discussion about the possible effect of housing benefit and social renting on mobility, we also include individual level dummies in the rental models to indicate whether the individual is a Local Authority renter or a housing benefit recipient at either the full $100 \%$ rate or a partial rate. It is possible (and indeed common) for individuals to live in local authority housing and receive housing benefit. The mobility effect of receiving housing benefit in the private sector may be different (where the effect on mobility may be smaller, particularly for those receiving partial housing benefit), so we also include interactions of receipt of housing benefit and being a Local Authority (LA) renter.

Looking first at the effect of being an LA renter on mobility we can see that, as expected, being a social renter is strongly negatively associated with moving both within and across regions. This effect is mitigated to some extent if the social renter also receives a $100 \%$ housing benefit or a partial housing benefit. Recipients of such housing benefits typically

\footnotetext{
${ }^{14}$ In Britain we also include a dummy variable to capture the years 1991 and 1992 where the poll tax regime was in place.
} 
have low current incomes and would have less difficulty qualifying for social council housing in another place if they did move. For renters in the private sector, receiving $100 \%$ housing benefit discourages mobility overall, but encourages cross-region mobility. Those receiving $100 \%$ housing benefit have no incentive to downsize as they will be consuming less housing with no offsetting reduction in cost. This would explain the negative effect on overall mobility. Private market rental coupled with receipt of partial housing benefit is not statistically significantly associated with differential mobility, which accords with our earlier discussion that the negative incentive to downsize is much less when rent is only partially covered by housing benefit.

The estimated impacts of amenity variables are more mixed, with only the January temperature measure indicating consistent results. In the US higher January temperature deters mobility across states, but only for those less than 70 , with much stronger effects for owners than for renters. For moves which do not go across state boundaries, higher January temperature actually encourages mobility for renters and owners alike. As expected, these temperature-related effects are much weaker in Britain.

\section{CONCLUSIONS}

Housing wealth is a major component of individual retirement resources, and the dynamics of housing wealth trajectories at older ages are not well understood. But housing is also durable good providing, for homeowners at least, consumption services both contemporaneously and in the future. Consequently wealth trajectories need to be analyzed somewhat differently to other forms of wealth where one might naturally expect individuals to run down their wealth as they age in order to finance consumption in retirement.

When looking at trajectories of housing consumption (as measured by number of rooms) or housing wealth, differences between the US and Britain are driven not so much by differences in behavior of movers, but by differences in proportions of households who move. In this paper, we have investigated possible causes of these mobility differences, whether these be constraints in terms of the possible improvements that could be had by moving (in terms of climate etc.) or disincentives to move that may be inherent in the various national and state-level economic institutions.

We found a role for geographic, demographic, economic, and social factors that was surprisingly consistent across countries. In each case, the magnitude of the underlying variation in factors within each country leads to less housing mobility in Britain than the US. For example, whilst subsidized housing disincentivizes mobility in both countries, the higher proportion of subsidized renters in Britain (combined with a greater marginal effect of subsidized renting on mobility) leads to considerably less mobility in Britain. Similarly, while living in a colder or darker region leads to more mobility at older ages in both countries. The fact that regions differ by only one or two degrees (or one or two hours of sunshine) in Britain again leads to less mobility for older British households than for their American counterparts where state climate variation is much larger.

One obvious omission from our analysis is a measure of geographical proximity to other members of the family, and in particular children and grandchildren. While we do not have information on this in the individual level data we use in our analysis, the international differences are likely to be such that this would be in line with other effects we find. There is less geographical mobility at younger ages in Britain than there is in the US, and thus older adults are already closer to their families and their children's families in their working years. Hence if geographical proximity to family is a motivation for mobility at older ages, then it is likely to lead to more mobility in the US than in Britain. 
There are likely to be important consequences of our analysis for understanding consumption trajectories at older ages. First, it suggests that in order to understand total consumption trajectories at older ages, one needs to first understand constraints placed on housing and location choices and various disincentives to housing mobility that might be in place. The institutional constraints on mobility, especially in Britain, imply relatively flat housing consumption profiles at older ages. Hence mobility choices, constraints, and outcomes may have knock-on effects to non-housing consumption either indirectly through the budget constraint (in the case that preferences are such that non-housing consumption is separable from housing) or even directly (when preferences are non-separable).

Understanding consumption and wealth trajectories at older ages is important for policy purposes and provides a possible test of the life-cycle model.

As an initial investigation into the potential for these impacts on non-housing consumption, Figure 3 plots the percent change in non-housing expenditures after age 50 in Great Britain and the United States. To calculate these non-housing expenditure profiles we used successive cross sections from the two best consumption micro-data sets in both countriesthe Consumer Expenditure Survey (CEX) in the United States, and the Family Expenditure Survey (FES) in Britain over the period 1987-2007. We select the cohort aged 55-59 in 1987 (i.e., those born between 1928 and 1932) in each country and plot average non-housing expenditures against age as successive random samples of that cohort are interviewed in successive years of the relevant surveys. In both countries, these changes are normalized to zero at age 50. The Figure demonstrates clearly that non-housing expenditures fall much faster with age for this cohort in Britain than they do in the United States. Of course, there are other institutional differences between the countries at older ages, especially regarding the much greater subsidies to medical expenditures in Britain that would need to be taken into account in a fuller analysis. Nevertheless, the Figure does suggest that there may be important implications of differential housing mobility in the two countries-especially as induced by their differing institutional subsidies and frictions-for other central economic behaviors that are worthy of future research.

\section{Acknowledgments}

The authors gratefully acknowledge the financial support by a grant from the National Institute on Aging R37AG025529. Banks Blundell and Oldfield are also grateful for additional cofounding from the ESRC under the auspices of the ESRC Centre for the Microeconomic Analysis of Public Policy at IFS. Smith benefited from the expert programming assistance of David Rumpel and Marion Oshiro. The usual disclaimer applies. We would like to thank Dan Feenberg of the NBER for his generous assistance with the NBER taxsim program.

\section{References}

BANKS J, BLUNDELL R, SMITH JP. Financial wealth inequality in the United States and Great Britain. Journal of Human Resources. 2003; 38:241-79.

BANKS, J.; BLUNDELL, R.; OLDFIELD, Z.; SMITH, JP. Housing price volatility and downsizing in later life. In: Wise, DA., editor. Research Findings in the Economics of Aging. Chicago: University of Chicago Press; 2010. p. 337-86.

BECKETTI S, GOULD W, LILLARD L, WELCH F. The Panel Study of Income Dynamics after fourteen years: An evaluation. Journal of Labor Economics. 1988; 6:472-92.

DIAMOND P. Income taxation with fixed hours or work. Journal of Public Economics. 1980; 13:10110.

DISNEY R, HENLEY A, STEARS G. Housing costs, house price shocks and savings behaviour among older households in Britain. Regional Science and Urban Economics. 2002; 32:607-25.

FITZGERALD J, GOTTSCHALK P, MOFFITT R. An analysis of sample attrition in panel data: The Michigan Panel Study of Income Dynamics. Journal of Human Resources. 1998; 33:251-99. 
GRIFFITH R, DEVEREUX M. Taxes and the location of production: Evidence from a panel of multinationals. Journal of Public Economics. 1998; 3:335-67.

MERRILL, SR. Home equity and the elderly. In: Aaron, H.; Burtless, G., editors. Retirement and Economic Behavior. Washington DC: The Brookings Institution; 1984.

SHEINER, L.; WEIL, D. National Bureau of Economic Research Working Paper No 4115. 1992. The Housing Wealth of the Aged.

VENTI, S.; WISE, D. Aging and housing equity: Another look. In: Wise, DA., editor. Perspectives on the Economics of Ageing. Chicago: Chicago University Press; 2001. p. 127-80.

VENTI, SF.; WISE, DA. Aging, moving and housing wealth. In: Wise, DA., editor. The Economics of Aging. Chicago: University of Chicago Press; 1989.

VENTI, SF.; WISE, DA. But they don't want to reduce housing equity. In: Wise, DA., editor. Issues in the Economics of Aging. Chicago: University of Chicago Press; 1990. 


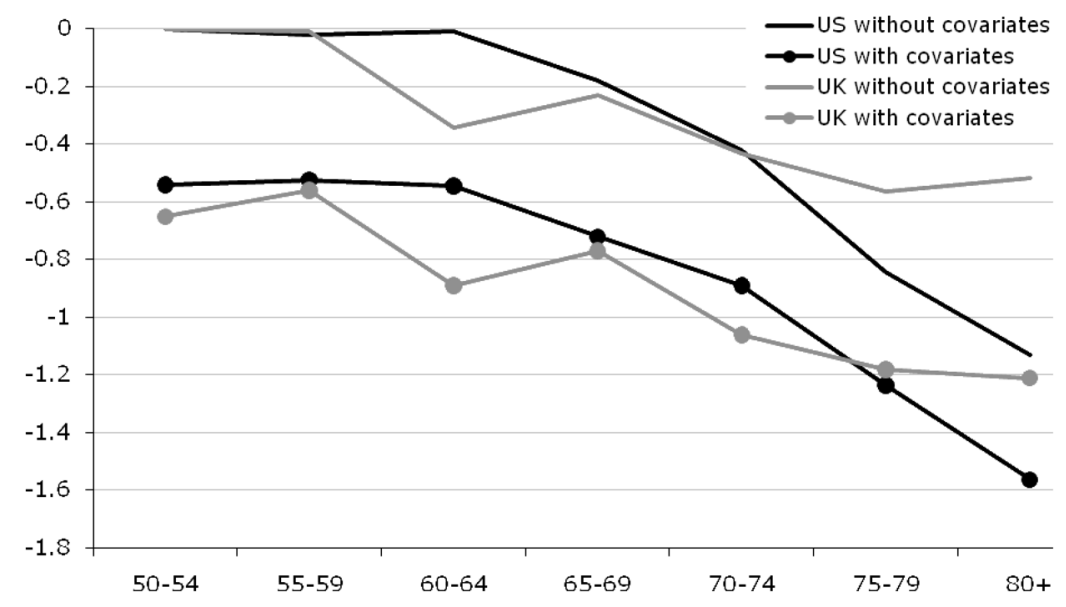

Figure 1. Normalised change in number of rooms by age, movers only

Note: Figure 1 depicts change in number of rooms across age groups normalized to zero change in age band 50-54. These changes are provided based on a model that only includes age dummies for each age band, and a model that also includes measures of changes in family composition for spouse and children living at home and changes in employment status. These models are estimated using PSID and BHPS data (see Banks et al. (2010) for further details). 


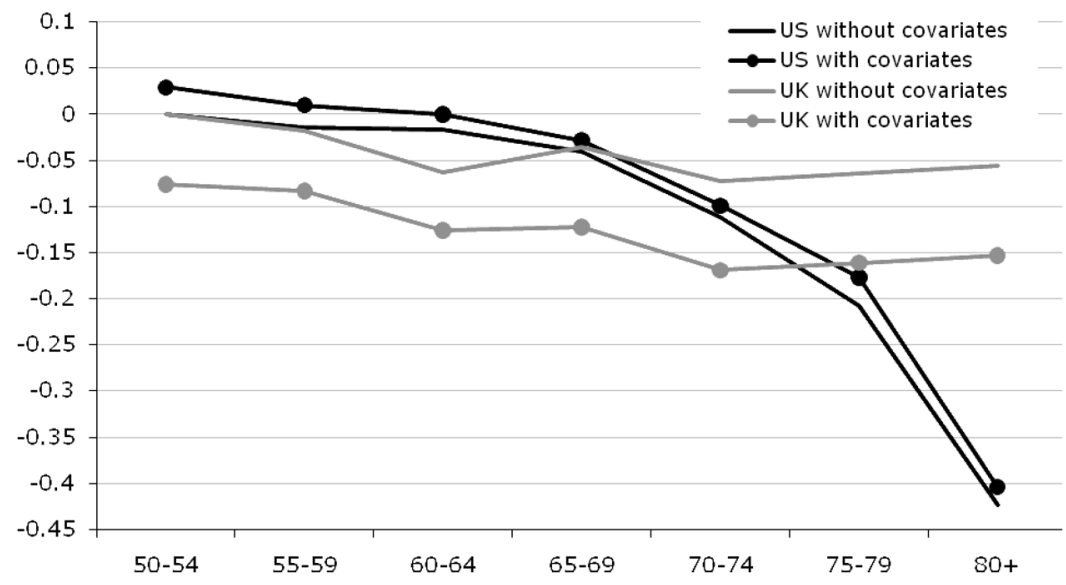

Figure 2. Normalised change in number of rooms by age, all households Note: See notes to Figure 1. 


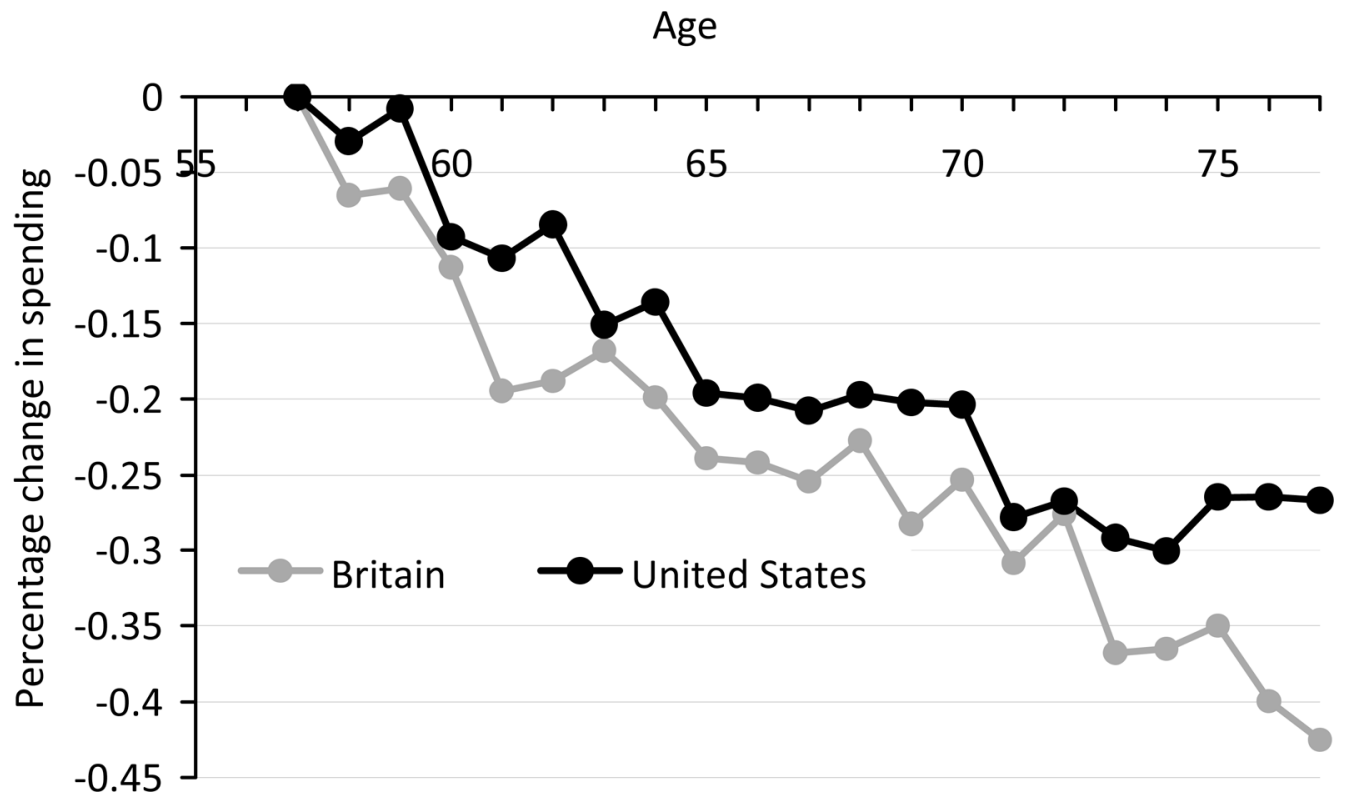

Figure 3. Percentage Change in Non-Housing Expenditure with Age Notes: Figure 3 shows the percentage change in spending on non-housing items of expenditure by age, normalized at age 58. Data for Britain is based on data from the Expenditure and Food Survey and its predecessor the Family Expenditure Survey and data for the US is based on the Consumer Expenditure Survey. Data from both countries covers the period from 1987 to 2007. 


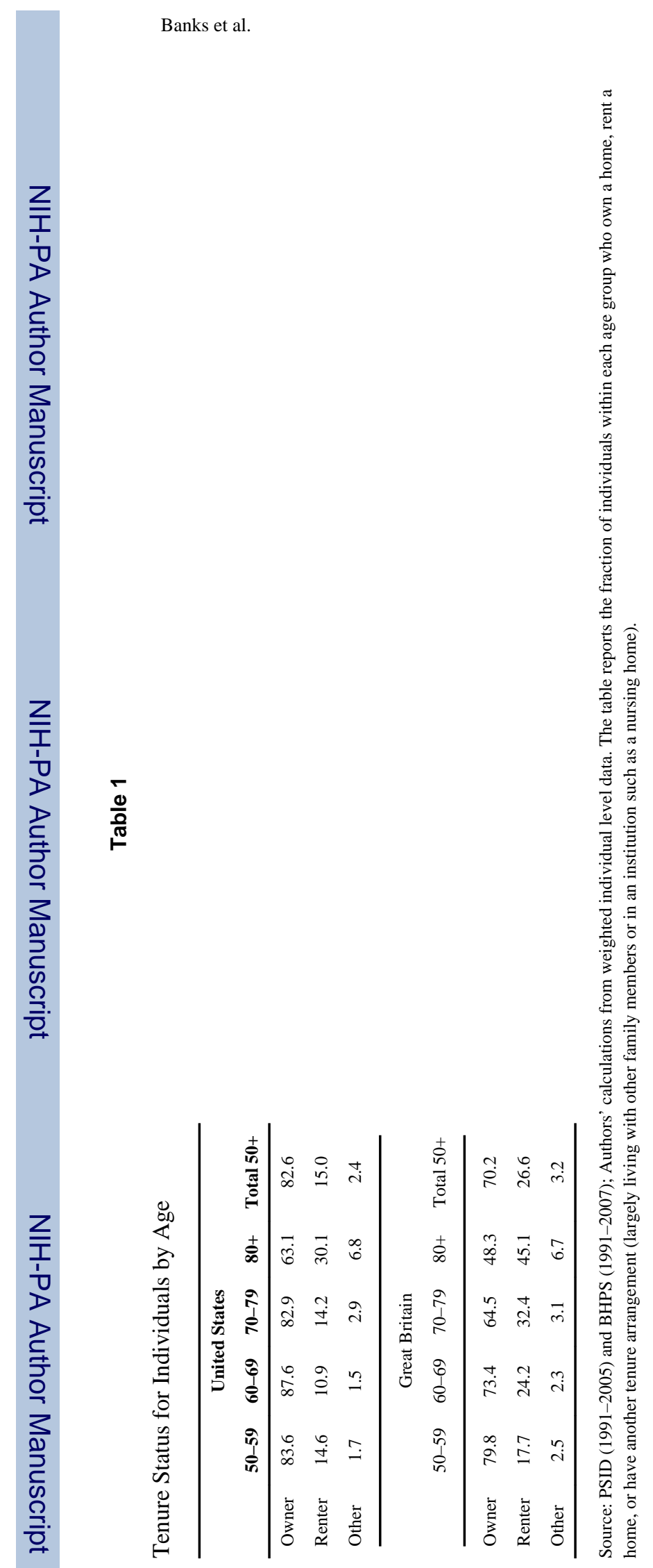

Economica. Author manuscript; available in PMC 2013 July 23. 


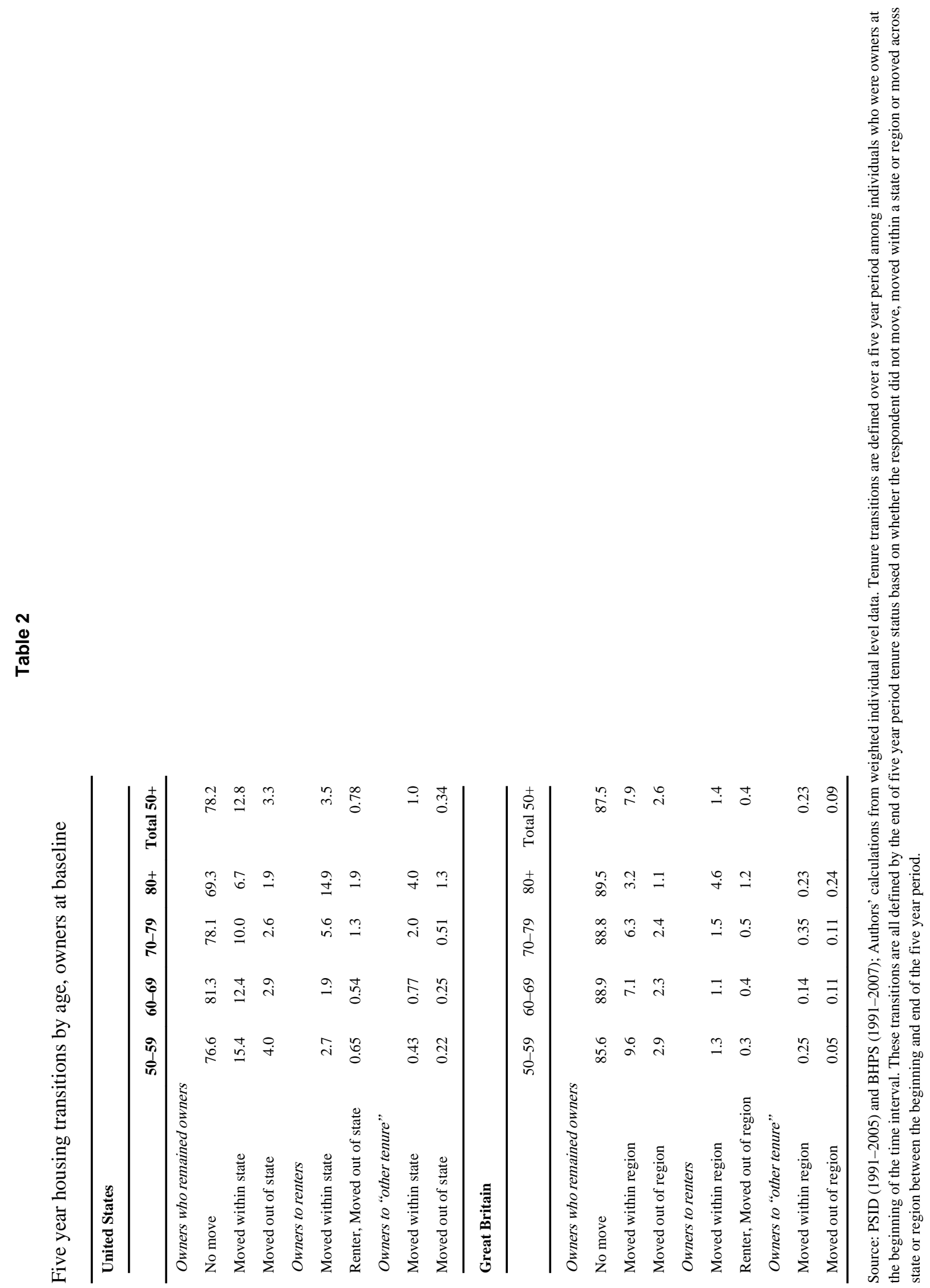




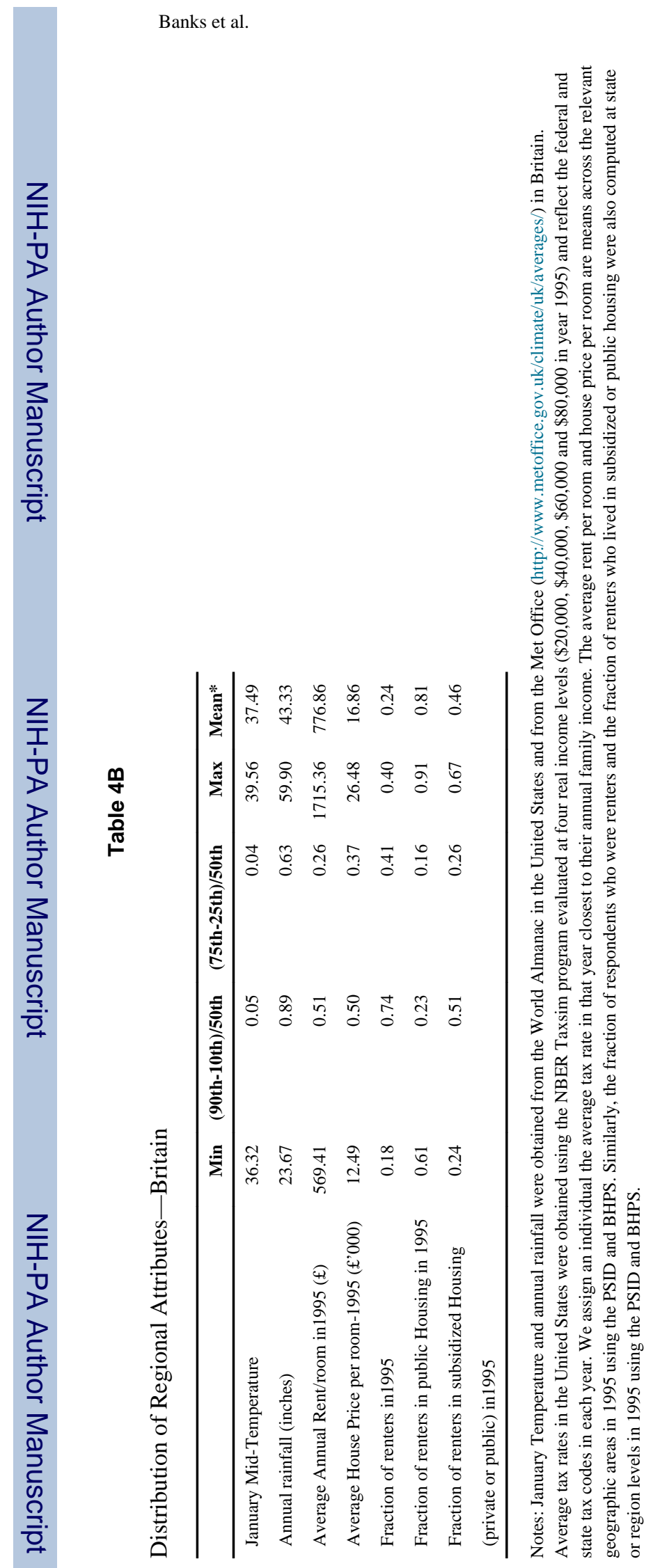

Economica. Author manuscript; available in PMC 2013 July 23. 
Table 5

Mobility Among British Renters

\begin{tabular}{lrc}
\hline Renter Type & \% of Renters & Prob of moving in five years \\
\hline Social, no benefit & 36.8 & 0.14 \\
Social, partial benefit & 25.7 & 0.16 \\
Social, 100\% benefit & 17.8 & 0.22 \\
All social renters & $\mathbf{8 0 . 3}$ & $\mathbf{0 . 1 6}$ \\
Private, no benefit & 10.3 & 0.35 \\
Private, partial benefit & 2.0 & 0.34 \\
Private, 100\% benefit & 7.5 & 0.40 \\
All private renters & $\mathbf{1 9 . 7}$ & $\mathbf{0 . 3 7}$ \\
\hline
\end{tabular}

Note: Social renters in Britain are those who live in public or Council housing. Private renters are those who live in private rental housing. We separate each group by whether they receive no housing benefit (a cash transfer to renters for housing), a partial benefit, or a $100 \%$ benefit. 


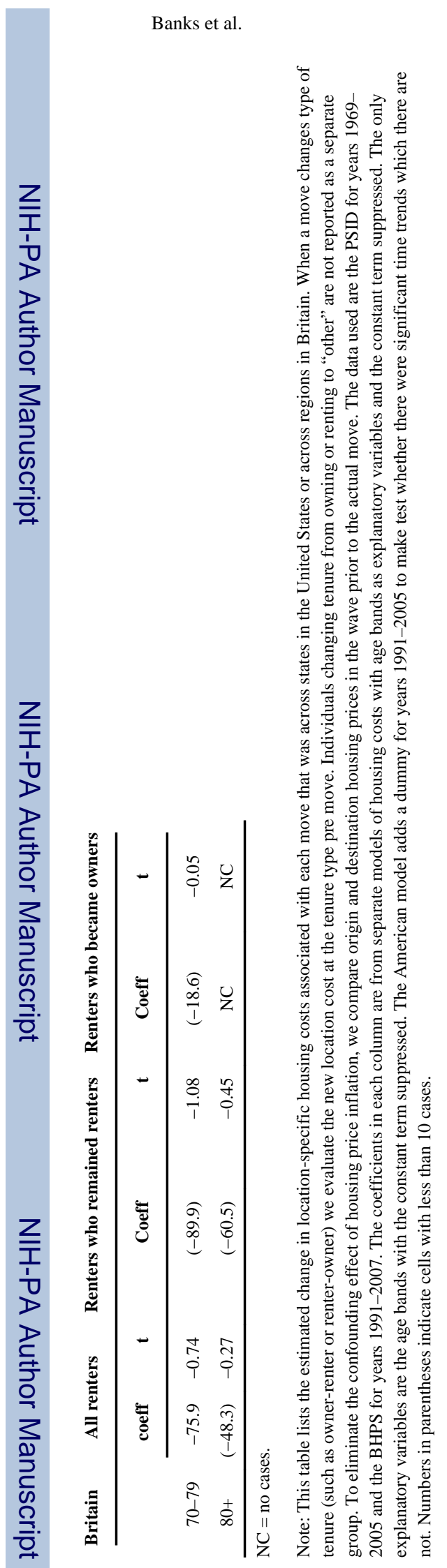

Economica. Author manuscript; available in PMC 2013 July 23. 


\section{Table 8}

Change in U.S. Tax Rates Associated with Mobility Individuals Who Moved Across States

\begin{tabular}{crr}
\hline & \multicolumn{2}{r}{ Income Tax Rate } \\
\cline { 2 - 3 } & coeff & $\mathbf{t}$ \\
$50-59$ & -0.018 & -6.06 \\
$60-69$ & -0.018 & -5.42 \\
$70-79$ & -0.015 & -3.35 \\
$80+$ & 0.001 & 0.19 \\
$1991-2005$ & 0.002 & 0.66 \\
\hline
\end{tabular}

Note: Data used are the PSID for years 1969-2005. Coefficients reported are from a model for change in tax rates where the only explanatory variables are the age bands with the constant term suppressed and a dummy for the years 1991-2005. Average tax rates in the United States were obtained using the NBER Taxsim program evaluated at four real income levels $(\$ 20,000, \$ 40,000, \$ 60,000$ and $\$ 80,000$ in year 1995$)$ and reflect the federal and state tax codes in each year. We assign an individual the average tax rate in that year closest to their annual family income in the year of the move for the origin and destination state. 


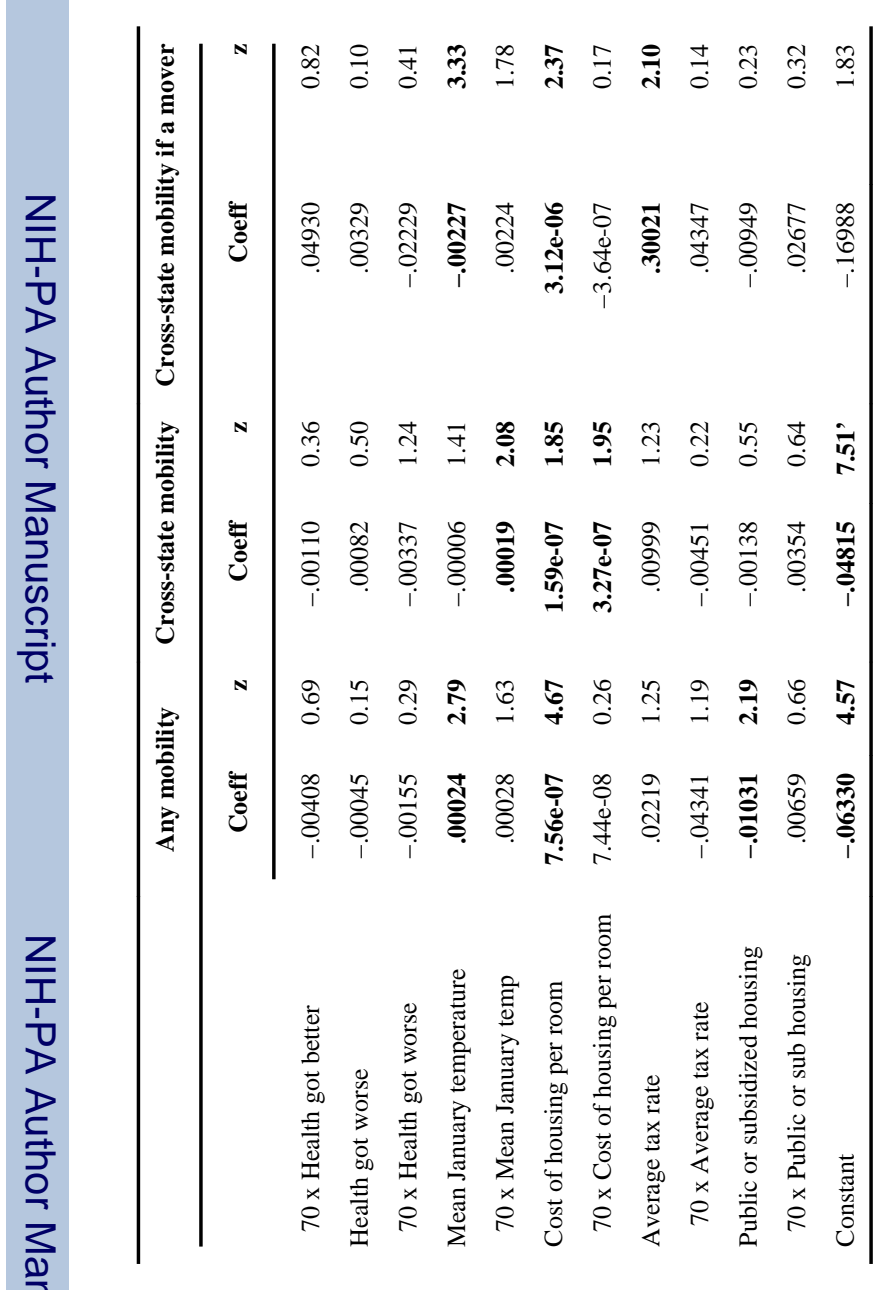

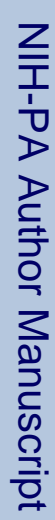




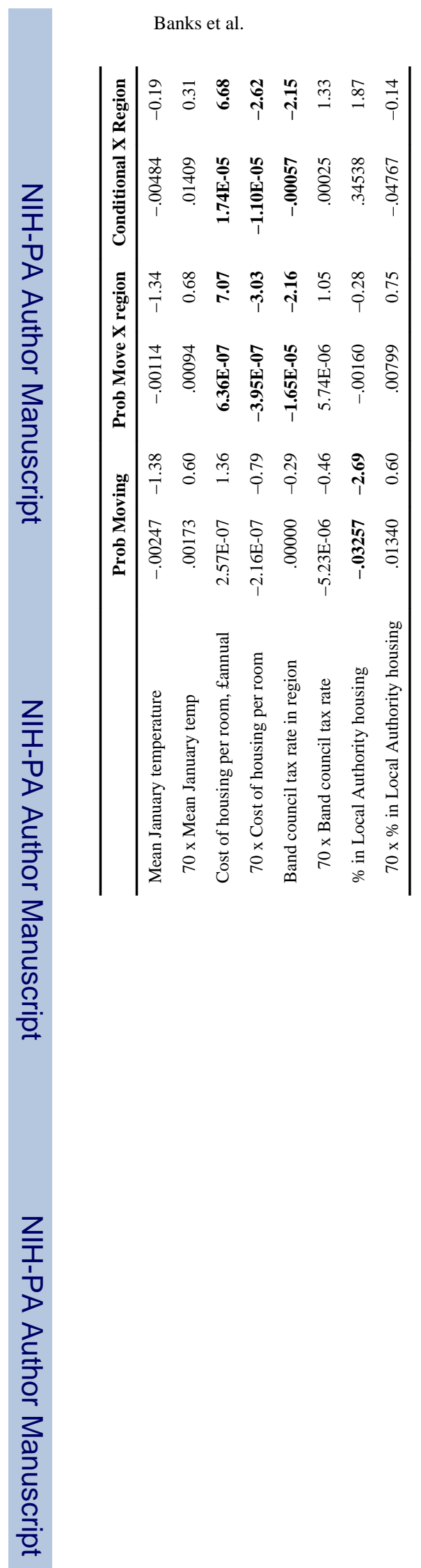

Economica. Author manuscript; available in PMC 2013 July 23. 


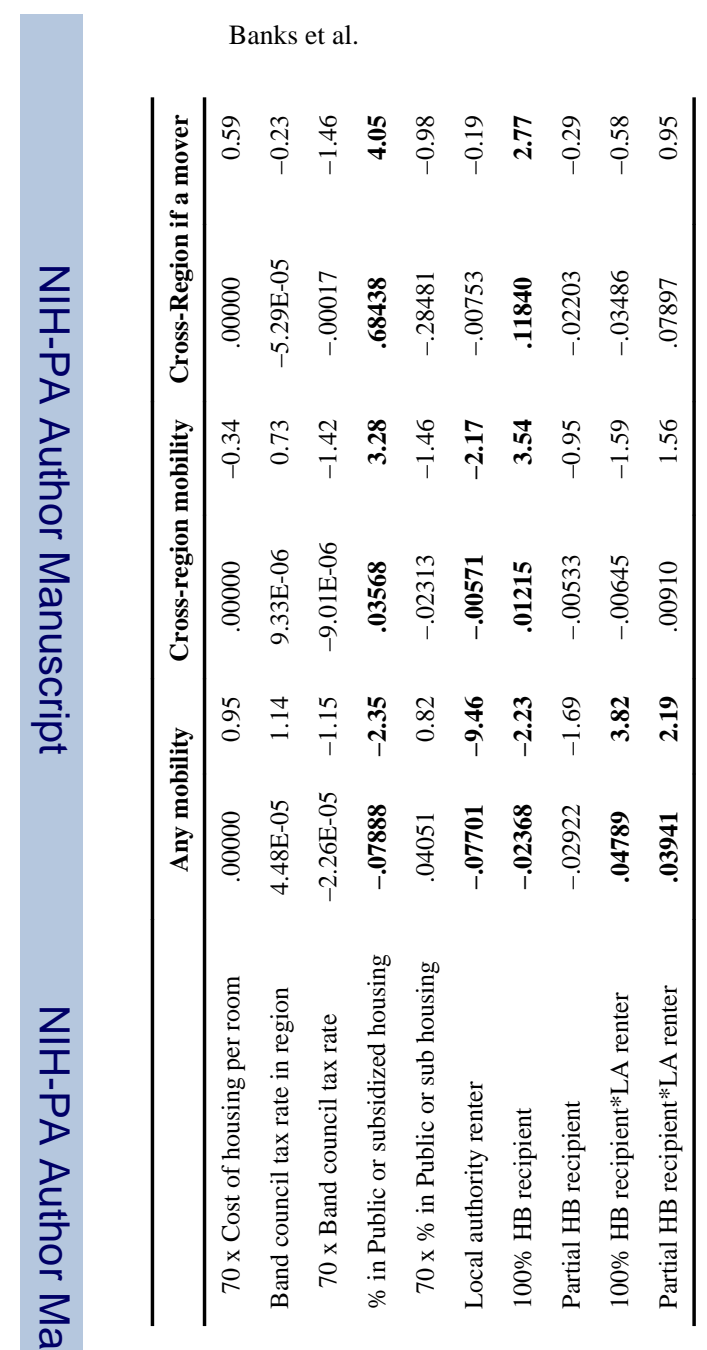

Page 37 